\title{
The infection of primary avian tracheal epithelial cells with infectious bronchitis virus
}

\author{
Ching-I SHEN ${ }^{1}$, Ching-Ho $\mathrm{WANG}^{2}$, Jiunn-Wang LiAo ${ }^{3}$, Tien-Wang $\mathrm{Hsu}^{4}$, \\ Shu-Ming $\mathrm{KuO}^{4}$, Hong-Lin $\mathrm{Su}^{4 *}$ \\ ${ }^{1}$ Department of Veterinary Medicine, National Chung-Hsing University, 250, Kuo-Kuang Rd., \\ Taichung, 402, Taiwan, Republic of China \\ ${ }^{2}$ School of Veterinary Medicine, National Taiwan University, No. 1, Sec. 4, Roosevelt Rd., Taipei, 106, \\ Taiwan, Republic of China \\ ${ }^{3}$ Graduate Institute of Veterinary Pathobiology, National Chung-Hsing University, 250, Kuo-Kuang Rd., \\ Taichung, 402, Taiwan, Republic of China \\ ${ }^{4}$ Department of Life Sciences, National Chung-Hsing University, 250, Kuo-Kuang Rd., Taichung, 402, \\ Taiwan, Republic of China
}

(Received 19 July 2009; accepted 24 September 2009)

\begin{abstract}
Here we introduce a culture system for the isolation, passaging and amplification of avian tracheal epithelial (ATE) cells. The ATE medium, which contains chicken embryo extract and fetal bovine serum, supports the growth of ciliated cells, goblet cells and basal cells from chicken tracheas on fibronectin- or matrigel-coated dishes. Non-epithelial cells make up less than $10 \%$ of the total population. We further show that ATE cells support the replication and spread of infectious bronchitis virus (IBV). Interestingly, immunocytostaining revealed that basal cells are resistant to IBV infection. We also demonstrate that glycosaminoglycan had no effect on infection of the cells by IBV. Taken together, these findings suggest that primary ATE cells provide a novel cell culture system for the amplification of IBV and the in vitro characterization of viral cytopathogenesis.
\end{abstract}

tracheal epithelial cell / infectious bronchitis virus / basal cell / primary culture / glycosaminoglycan

\section{INTRODUCTION}

Embryonated egg inoculation is commonly used to amplify avian RNA viruses. Successful viral replication mainly depends upon viral adaption to and replication in the cells of the embryonic and extraembryonic tissues. Growth retardation and malformation of the embryo are the main indicators of viral reproduction in this system and signal the proper period for harvesting the amplified virions from the amniotic or chorioallantoic fluids.

The low efficiency of viral amplification may prevent etiology determinations, intensive

\footnotetext{
* Corresponding author: suhonglin@nchu.edu.tw
}

surveillance of epidemiology and the tracing of potential natural domestic hosts for viral pathogens during an outbreak. For instance, avian metapneumovirus (MPV), which primarily attacks the respiratory tract, replicates inefficiently in embryonic eggs. Diagnosis of MPV infection is mainly dependent on the detection of viral RNA or viral antigens, but not viral isolation $[5,6]$. In addition, to investigate the epidemiology of avian influenza viruses (AIV) requires efficient and sensitive viral detection and amplification system for comprehensive collection of the viruses from waterfowl and migratory birds $[17,31]$. However, the wildbird isolated AIV are usually mildly or nonpathogenic to chicken embryos $[20,26]$ and

This is an Open Access article distributed under the terms of the Creative Commons Attribution-Noncommercial License (http://creativecommons.org/licenses/by-nc/3.0/), which permits unrestricted use, distribution, and reproduction in any noncommercial medium, provided the original work is properly cited. 
the efficiency of viral isolation is often unsatisfactory in embryonated eggs [11, 19].

It has been shown that serial passage using chicken embryos enforces the selection of adapted viruses and inevitably alters the genetic codes of the primary viral isolates, especially for genes involved in cell adsorption and viral replication $[8,9]$. The environment of the viral replication may also selectively modify the original cell tropism and pathogenesis of the isolated virus $[15,25]$. It has been shown that a serially embryo-passaged of infectious bronchitis viruses (IBV) M41 strain exhibited significantly attenuated pathogenesis within the oviduct compared to the parental strain [7]. In addition, egg-mediated epitope alterations in amplified isolates might attenuate the protective efficiency of these viruses when used to vaccinate against the challenge of a wild-type virulent strain [16, 24]. For instance, after egg adaption, human influenza A virus, originally showing \&2-6 sialic acid tropism only, exhibits increased hemagglutinin (HA) binding affinity to $\alpha 2-3$ sialic acid-containing gangliosides due to amino acid substitutions in the vicinity of the receptor binding site of the HA protein $[8,15]$. For primary viral isolates, providing natural host cells for replication might eliminate the selection pressure of an exotic growth environment and avert the alteration of cell tropism and consequent genomic mutations.

Recently, a study reported a primary culture system for tracheal epithelial cells from an embryonic day (E) 17 chick embryo, in which dissociated culture cells exhibited ciliary movement and were positive for the expression of pan-cytokeratin [33]. In addition, the global profile of mRNA expression in the cultured cells showed that cytokeratin 14 (K14), a basal cell marker, was highly expressed. However, the protein expression of cell-type specific markers and the existence of mucin-secreting goblet cell are not well-characterized. In this study, we developed a novel culture system to isolate, amplify and passage chicken tracheal epithelial cells in an efficient manner. The avian tracheal epithelial (ATE) cell types were identified using immunocytostaining, and the ratio of cell types is statistically illustrated. We further demonstrate that primary ATE cells support IBV replication. The susceptible cell types and the effect of glycosaminoglycan (GAG) on IBV attachment to ATE cells was also investigated.

\section{MATERIALS AND METHODS}

\subsection{Viruses and cell lines}

Two IBV, 2575/98 and 2296/95, were isolated in Taiwan and maintained using serial passage through specific pathogen-free (SPF) eggs [29]. IBV were inoculated into the embryonic eggs at the E9 stage and harvested at the E11 stage from chorioallantoic fluid. The original viral titers of 2575/98 and 2296/ 95 are $10^{7.4} \mathrm{EID}_{50} / 0.1 \mathrm{~mL}$ and that of 2296 reached $10^{9.6} / 0.1 \mathrm{~mL}$, respectively [14]. The applied viral titer of both IBV was $1 \times 10^{5} \mathrm{EID}_{50} / \mathrm{mL}$.

Plaque-purified Taiwan-isolated Japanese encephalitis virus (JEV) strain RP-9 [28] was used as a positive control for the study of GAG effect on the virus-cell attachment. The adsorption of JEV was performed with serum-free RPMI medium at $37{ }^{\circ} \mathrm{C}$ for $1 \mathrm{~h}$. Virus-infected cells were incubated in RPMI containing $2 \%$ fetal bovine serum (FBS). Virus titers were determined by plaque assay in BHK-21 (baby hamster kidney) cells, which were maintained in RPMI 1640 with $5 \%$ FBS, $2 \mathrm{mM}$ L-glutamine, $100 \mathrm{mg} / \mathrm{mL}$ of streptomycin, and $100 \mathrm{IU} / \mathrm{mL}$ of penicillin. The medium and culture reagents are obtained from Invitrogen (Carlsbad, CA, USA).

\subsection{Primary culture of ATE cells}

Tracheas were obtained from one-day-old SPF chicks and rinsed in DMEM medium (Invitrogen) under sterile conditions. After the removal of surrounding adipose and muscular tissues, tracheas were digested with dispase I solution $(2.5 \mathrm{U} / \mathrm{mL}$ dispase I) (Roche, Nutley, NJ, USA) for $2 \mathrm{~h}$ at $37{ }^{\circ} \mathrm{C}$ to disrupt the basal membrane. Forceps were used to force the outflow of detached cell sheets of tracheal epithelium from the tracheal lumen. The epithelial cells were harvested and further digested with collagenase I ( $1 \mathrm{mg} / \mathrm{mL}$, Roche) for $5 \mathrm{~min}$ at $37{ }^{\circ} \mathrm{C}$. The cells were gently pipetted, and the tissues were homogenized into small cell clumps. FBS was added to the digesting solution to stop the reaction. The cells were centrifuged at $1000 \mathrm{rpm}$ for $5 \mathrm{~min}$ to remove residual digesting enzymes. The cell pellets were resuspended in ATE medium, containing 10\% FBS (Invitrogen), $10 \%$ chicken embryo extract (CEE) (US Biological, 
Swampscott, MA, USA; or self-made [27]), 1\% glutamine (Invitrogen), $0.1 \mathrm{mM} \quad \beta$-mercaptoethanol (Sigma-Aldrich, St. Louis, MO, USA), 1\% nonessential amino acids (Invitrogen) and 1\% penicillin/streptomycin (Invitrogen) in DMEM-F12 medium (Invitrogen). Cells were seeded on 2\% matrigel- or $20 \mu \mathrm{g} / \mathrm{mL}$ fibronectin-coated 24-well or 96-well plates (Corning Inc., Corning, NY, USA). When the cells reached confluence, the cultured cells were passaged by digestion with both $0.01 \%(\mathrm{w} / \mathrm{vol})$ protease (type XIV, Sigma-Aldrich) and $2.5 \mathrm{U} / \mathrm{mL}$ dispase I for $5 \mathrm{~min}$ at $37^{\circ} \mathrm{C}$.

\subsection{Chemicals}

GAG compounds, including the heparin $(\mathrm{H})$, heparan sulfate (HS), dextran sulfate (DS) and chondroitin sulfate (CS), were obtained from Sigma-Aldrich. The MTT (3-(4,5-dimethylthiazol-2-yl)-2,5-diphenyltetrazolium bromide) assay kit was obtained from Sigma-Aldrich. FITC-conjugated BSI-B4 isolectin (Sigma-Aldrich) was used as a marker for basal cells from the tracheal epithelium [12]. Commercial culture media for human and rat airway epithelial cells were obtained from CELLnTEC advanced cell system (Postfach, Bern, Switzerland) and CELL Applications Inc. (San Diego, CA, USA), respectively.

\subsection{Immunohistostaining and immunocytostaining}

Cells or cryosections of infected trachea were fixed in $4 \%$ cold paraformaldehyde and permeabilized with $0.3 \%$ Triton-X 100 . Immunocytochemistry was performed with the following primary antibodies: E-cadherin (1:500, BD Biosciences, Franklin Lakes, NJ, USA), $\beta$-tubulin IV and pan $\beta$-tubulin (1:100, Sigma), ZO-1 (1:100, Zymed-Invitrogen), mucin 5AC (1:50, Abcam, Cambridge, MA, USA), cytokeratin 14 (1:100, Convance, Princeton, NJ, USA), smooth muscle actin (SMA, 1:50, DakoCytomation, Glostrup, Denmark) and vimentin (1:500, Convance). Immune-serum of IBV-infected chicken, screened by ELISA, was used for the detection of IBV antigens in infected cells (1:200) [30]. Fixed cells were washed twice with $0.1 \%$ Tween- 20 in phosphate buffer saline (PBS). Appropriate fluorescence-tagged secondary antibodies (all from Jackson ImmunoResearch, West Grove, PA, USA) were used for visualization. Blue 4',6-Diamidino-2-phenylindole (DAPI) was used for nuclear counter-staining. Images of immunostaining were captured using a fluorescent microscope (Nikon ECLIPSE 80I) or confocal microscope (LSM510 Meta, Zeiss).

\subsection{Reverse transcription-polymerase chain reaction (RT-PCR)}

Total RNA was extracted from TW2575/98infected ATE cells using TRIzol ${ }^{\mathrm{TM}} \mathrm{C} \& \mathrm{~T}$ (Protech, Taiwan) according to the manufacturer's protocol. Positive-sense and negative-sense viral RNA $(0.5 \mu \mathrm{g})$ were reverse transcribed into cDNA using SuperScript ${ }^{\mathrm{TM}}$ III reverse transcriptase (RT) (Invitrogen) with oligo dT and sense primer $5^{\prime}$-ACT GAA AAT GAT AGT GTT ATG-3', respectively. PCR was performed with a proofreading DNA polymerase (KOD-Plus, Toyobo, Osaka, Japan). The PCR cycling conditions consisted of 28 cycles at $94{ }^{\circ} \mathrm{C}$ for $30 \mathrm{~s}, 62{ }^{\circ} \mathrm{C}$ for $30 \mathrm{~s}$, and $68^{\circ} \mathrm{C}$ for $1 \mathrm{~min}$ on a PCR machine (ASTEC 818). The primer sequences for detection of the nucleocapsid gene of IBV were 5'-AAT GCA TCT TGG TTT CAA GC-3' and 5'-TCC TCA TCT GAG GTC AAT GC-3'; for detection of GAPDH, the sequences were $5^{\prime}$-GTG AAG GTC GGT GTG AAC G3' and 5'-GGT GAA GAC ACC AGT AGA CAC TC-3'.

\subsection{The effect of GAG on JEV and IBV infections}

The effect of GAG on JEV and IBV infections was measured in BHK-21 cells and ATE cells, respectively. The cells were seeded at a density of $5 \times 10^{3}$ cells/well in 96-well plates. The GAG were serially diluted and applied at $0,7.5,15$, and $30 \mu \mathrm{g} / \mathrm{mL}$ for BHK-21 cells and at $0,0.5,1.0$, $2.0 \mathrm{mg} / \mathrm{mL}$ for ATE cells. The BHK-21 and ATE cells were infected with 500 plaque-forming units of JEV and $10^{3} \mathrm{EID}_{50}$ of IBV at $37^{\circ} \mathrm{C}$ for $1 \mathrm{~h}$. Cells were washed three times with serum-free medium, and then normal growth medium was added. The number of infected cells per 96-well, revealed by IBV immunocytostaining, was manually counted at $8 \mathrm{~h}$ post-infection (h.p.i.) from five individual fields. No obvious cell damage was observed after GAG treatment or viral infection at 8 h.p.i. $[18,28]$.

\section{RESULTS}

\subsection{The establishment of primary ATE cells}

For the isolation of tracheal epithelial cells, the intact cell sheet of the tracheal epithelium was first isolated from dispase-treated tracheas (Fig. 1A). The epithelial membrane sheet was further mechanically disrupted into small pieces 


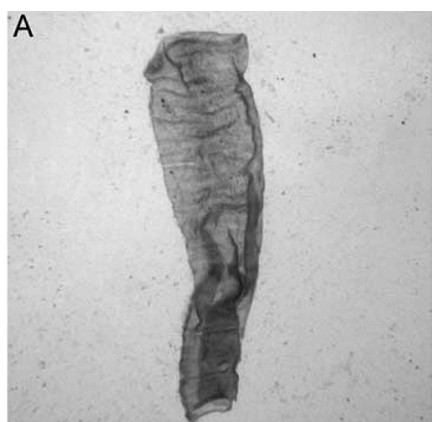

D

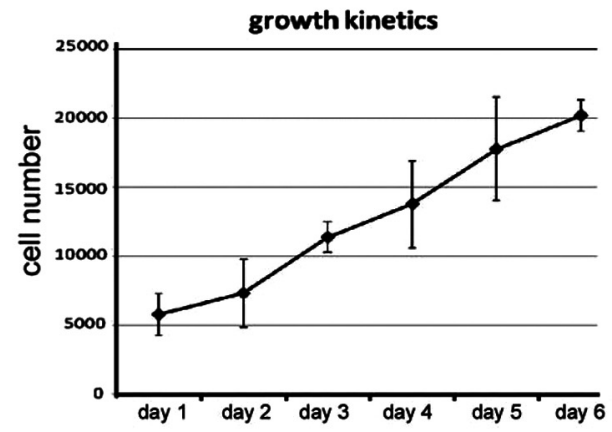

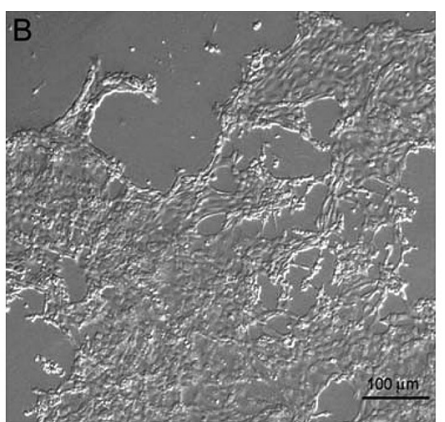

$E$

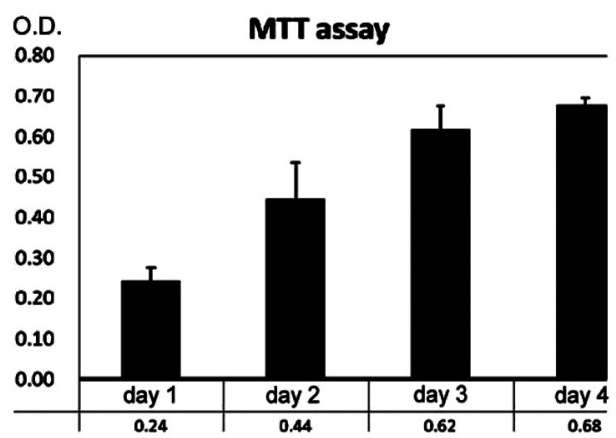

Figure 1. Morphology and growth curve of primary avian tracheal epithelial (ATE) cells. (A) An isolated intact membrane sheet of the tracheal epithelium from a one-day-old chick. After digestion with collagenase I, the dissociated ATE cells were plated on $2 \%$ matrigel-coated 24 -well plates. The morphology of the ATE cells are shown in panel (B) and (C). The cell growth was further analyzed by trypan blue exclusion assay (D) and MTT activity (E). Y-axis (D) states the cell number per well of 24-well plates.

by pipetting. Floating unattached ATE cells rapidly underwent cell death or growth arrest after a one-day culture. The optimal cell matrix for ATE cells was evaluated; both $2 \%$ matrigel or $20 \mu \mathrm{g} / \mathrm{mL}$ fibronectin efficiently promoted cell attachment, but gelatin, collagen I, collagen IV and laminin were less effective (data not shown).

The primary culture system for mammalian tracheal epithelial cells is well-established. To culture the ATE cells, specialized commercial media for the tracheal epithelia of humans and rats were first tested (described in the Materials and methods section). None of them supported cell growth or long-term viability of ATE cells. Adjustment of the concentration of retinoic acid, a differentiating factor for tracheal epithelial cells [10], did not affect attachment or cell growth of ATE cells. Increasing FBS from $10 \%$ to $20 \%$ in the culture medium modestly enhanced the viability of the cells (data not shown). We speculated that unidentified chicken nutrients essential for the promotion of ATE cell growth were absent in the culture medium. CEE, an essential supplement for the culture of mouse neural crest stem cells [27], was added to DMEM-F12 medium with $10 \%$ FBS. We found that CEE significantly improved cell growth and reduced cell death of the primary ATE cells (Figs. 1B and 1C). The cell number of initial harvest from one trachea on day 1 is about $2 \times 10^{5}$ cells. With this optimized culture medium, isolated cells displayed increased MTT activity, and the celldoubling time was $46 \mathrm{~h}$ during the first 6 days of culture (Fig. 1D). The ATE cells could sustain proliferative activity for 3-5 passages. These results show that the established culture system provides sufficient nutrients and proper 
growth conditions for the amplification of ATE cells.

\subsection{The cell types of ATE cells}

Tracheal epithelial cells are connected to each other by E-cadherin molecules [23]. Among the isolated ATE cells, $88.3 \pm 13.2 \%$ expressed E-cadherin and a gap-junction molecule, ZO-1 [23]. E-cadherin-negative cells, including SMA-positive muscle cells and vimentin-positive fibroblast cells, accounted for $5.0 \pm 1.4 \%$ and $3.5 \pm 1.2 \%$ of the cultured cells, respectively, indicating the high purity of this primary culture system. In tracheal epithelial cells, $\beta$-tubulin IV/ $\beta$-tubulin, mucin $5 \mathrm{AC}$ and cytokeratin 14 (K14) are specific markers of ciliated cells, goblet cells and basal cells, respectively $[12,13,23]$. Basal cells also show high affinity for GSI-B4, a plant lectin that specifically binds the glycoconjugates of basal cells of tracheal epithelia [12, 13]. Figure 2 shows that these three major cell types - ciliated cells, goblet cells and basal cells - were all present in the ATE population, and accounted for $22.8 \pm 9.1 \%, 44.8 \pm 9.7 \%$ and $41.6 \pm 8.4 \%$ of the ATE cells, respectively.

\subsection{ATE cells support IBV replication}

To determine whether ATE cells support the replication of IBV, two egg-adapted Taiwan IBV strains, 2575/98 and 2296/95, were used in this study. These two IBV viruses cannot infect primary chicken embryonic fibroblast cells or immortalized DF1 chicken fibroblast cells. The ATE cells $\left(5 \times 10^{4}\right)$ were infected with $50 \mu \mathrm{L} 2575 / 98 \quad\left(\mathrm{EID}_{50}=10^{5} / \mathrm{mL}\right)$ for $1 \mathrm{~h}$ at $37^{\circ} \mathrm{C}$. At 24 h.p.i., IBV proteins were detected in 2500-3000 cells by staining with chicken anti-serum against IBV (Fig. 3B). We found that the IBV only infected $\mathrm{N}$-cadherin ${ }^{+}$ tracheal epithelial cells, revealing that neither smooth muscle cells nor fibroblast cells are the major target cells for IBV infection (Figs. $3 \mathrm{D}$ and $3 \mathrm{E}$ ). The infection rate gradually increased to $55.3 \pm 12.8 \%$ of the total cells at 72 h.p.i. (Fig. 3C), as estimated by immunocytostaining for IBV antigens in all adherent cells. Similar results were observed in 2296/95- infected cells (data not shown). In addition, both positive- and negative-sense viral RNA present were detected in the cytosol, and positive-sense viral RNA could be detected in the supernatant of ATE cells at 24 h.p.i. (Fig. 3F), demonstrating that mature IBV virion could be produced and released from the cells. These results indicate that cultured ATE cells support viral infection, replication and spreading of IBV.

\subsection{IBV infects ciliated cells and goblet cells, but not basal cells}

It has been reported that IBV can infect both ciliated cells and goblet cells in the tracheal epithelium [1, 22]. However, whether basal cells are also susceptible to IBV infection remains obscure. We infected isolated intact tracheas with $50 \mu \mathrm{L} 2575 / 98 \quad\left(\mathrm{EID}_{50}=10^{5} / \mathrm{mL}\right)$ for $48 \mathrm{~h}$ and found that IBV protein expression only colocalized with $\beta$-tubulin IV- or mucin 5AC-positive cells (Figs. 4A and 4B). No viral protein was detected in the K14-positive basal cells of the tracheal epithelium (Figs. 4C and 4D). To further examine whether basal cells are resistant to IBV infection in vitro, $5 \times 10^{4}$ ATE cells were also infected with $50 \mu \mathrm{L}$ of IBV $2575 / 98$ strain $\left(10^{5} \mathrm{EID}_{50} / \mathrm{mL}\right)$ for $48 \mathrm{~h}$. In vitro results consistently showed that viral proteins of IBV were mainly detected in ciliated cells and goblet cells, but not in basal cells (Figs. 4E-4H). Similar cell tropism results were obtained when IBV 2296/95 or a higher dosage of viral loading was used (data not shown). These in vivo and in vitro experiments clearly delineate the cell tropism of IBV in the avian respiratory tract.

\subsection{GAG has no significant effect on IBV binding to ATE cells}

Virus binding to host cell surface receptors is critical for determining tissue tropism and viral pathogenesis. It has been shown that $\mathrm{H}$ or HS may serve as a coreceptor in fibroblast cells for infection by the IBV Beaudette strain, but not the M41 strain [18]. In this study, highly sulfated GAG, such as $\mathrm{H}$ and DS, and common GAG, such as HS and CS, were tested to 
A
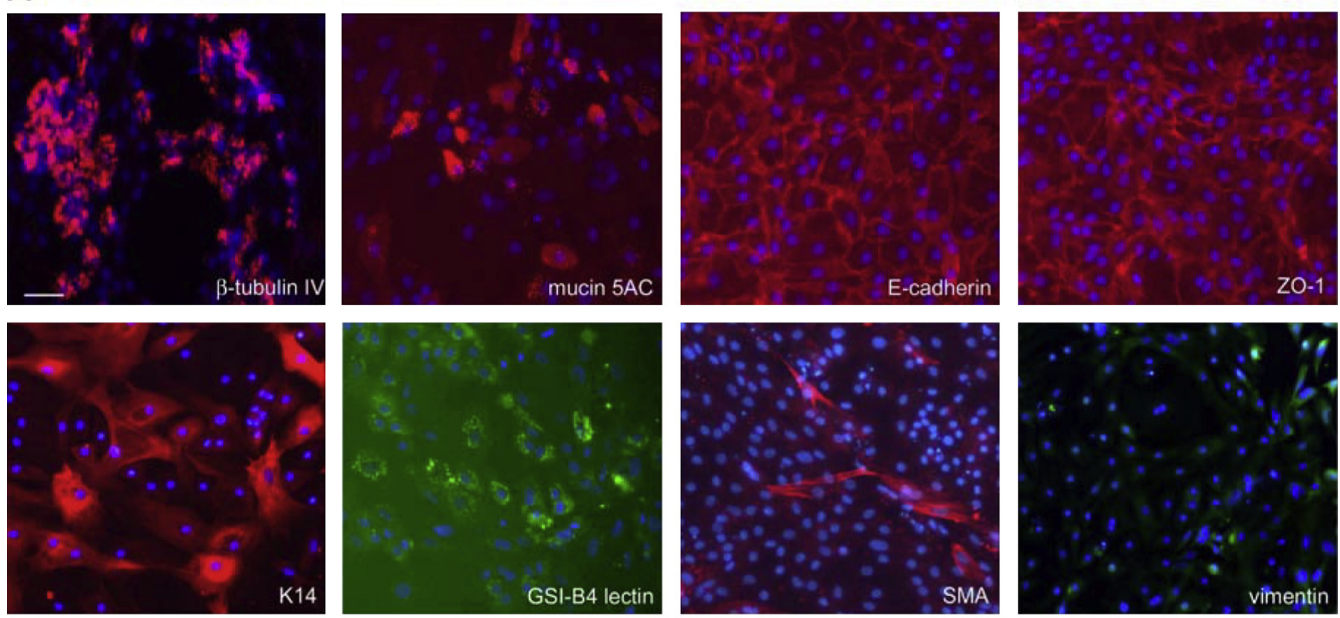

B

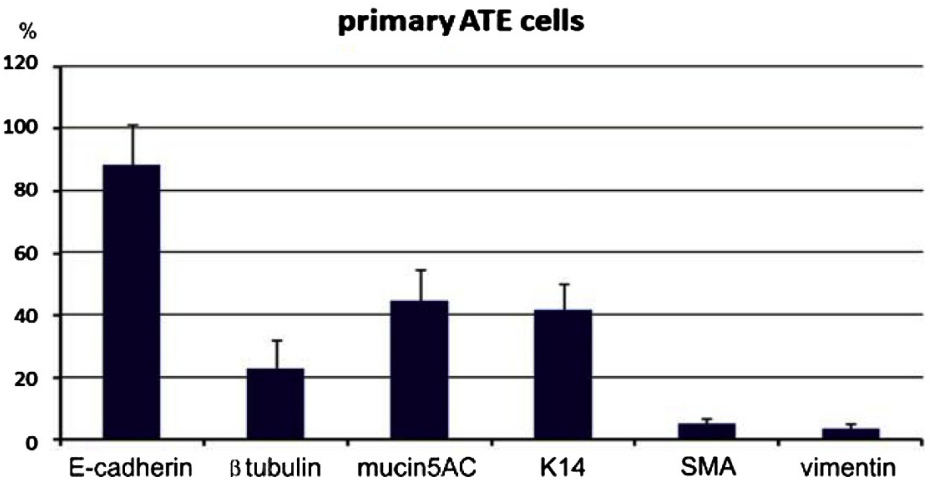

Figure 2. Cell identification and cell percentages of the primary ATE cells. The cell types of the cultured cells were identified by immunocytostaining. $\beta$-tubulin IV, ciliated cells; mucin 5AC, goblet cells; E-cadherin and ZO-1, epithelial cells; K14 and GSI-B4, basal cells; smooth muscle actin (SMA), smooth muscle cells; vimentin, fibroblast cells. The percentages of individual cell types among the ATE cells are illustrated. The data represent triplicate experiments that analyzed at least 500 counted cells. Scar bar, $25 \mu \mathrm{m}$. (A color version of this figure is available at www.vetres.org.)

determine whether they possess different neutralizing effects on binding of Taiwan-isolated IBV to ATE cells. JEV was used as a positive control for the evaluation of the GAG effect [28]. Figure 5A shows that both $\mathrm{H}$ and DS at $7.5 \mu \mathrm{g} / \mathrm{mL}$ effectively blocked JEV infection in BHK-21 cells, as previously reported [28]. Complete inhibition of JEV infection was achieved when the concentrations of $\mathrm{H}$ and DS were elevated to $30 \mu \mathrm{g} / \mathrm{mL}$. Although low concentrations of HS and CS did not affect JEV infection, a modest neutralizing effect was observed when the concentrations of HS and CS were elevated to $30 \mu \mathrm{g} / \mathrm{mL}$. In contrast to the JEV results, even when all of the tested GAG were applied at $2.0 \mathrm{mg} / \mathrm{mL}$, no significant inhibitory effects were observed on the infection of primary ATE cells by TW2575/98 (Fig. 5B). In addition, the GAG did not alter the cell tropism of IBV on cilia cells or goblet cells (data not shown). These results strongly suggest that the binding affinity of GAG for $\mathrm{IBV}$ is too low to interfere with viral entry into tracheal epithelial cells. 

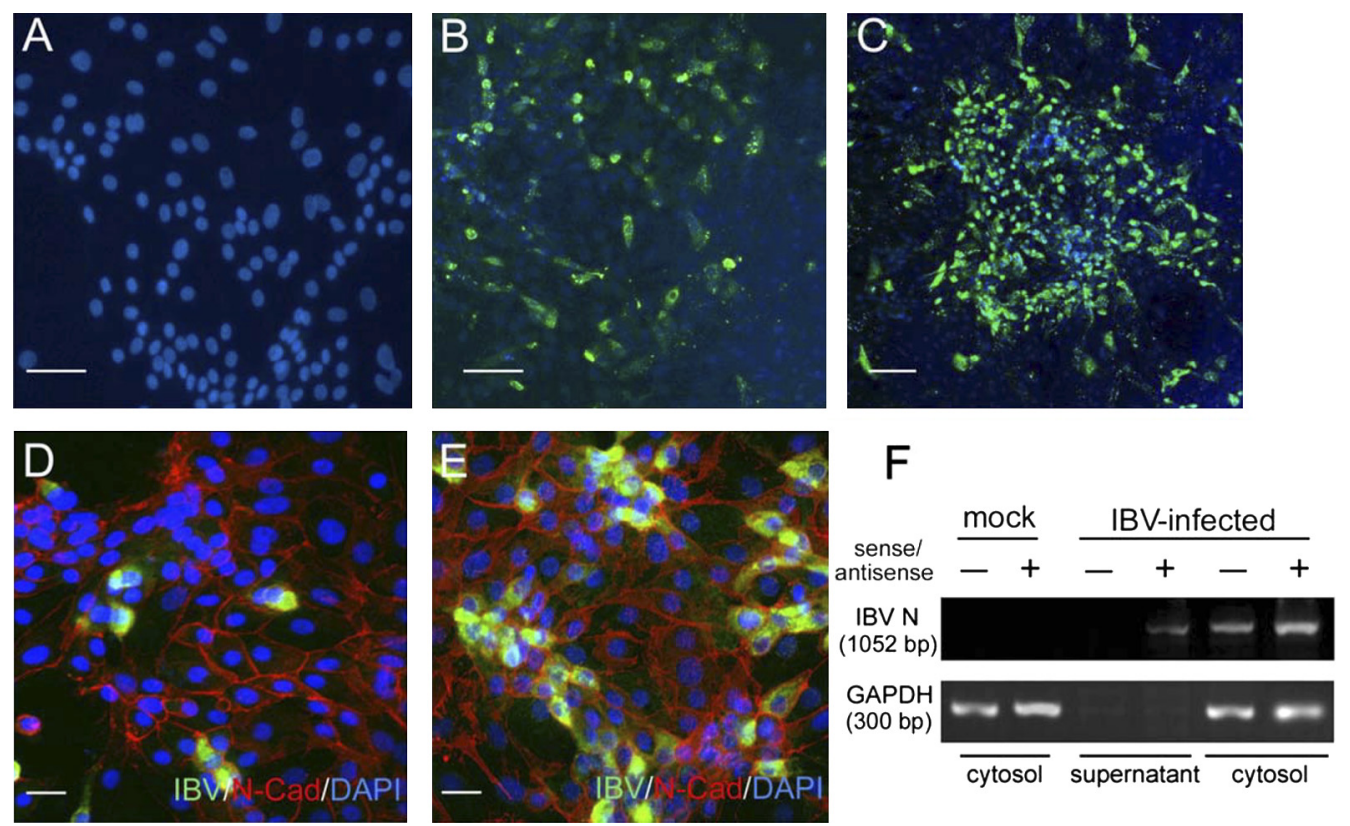

Figure 3. Infection of ATE cells with IBV. A total of $5 \times 10^{4}$ ATE cells were either non-infected (A) or infected with $50 \mu \mathrm{L}$ of $2575 / 98$ strain $\left(\operatorname{EID}_{50}=10^{5} / \mathrm{mL}\right)$ for $1 \mathrm{~h}$ at $37{ }^{\circ} \mathrm{C}$. At 24 h.p.i. (B, D) and 72 h.p.i. (C, E), the expression of IBV proteins was detected by chicken anti-serum against IBV (200-fold diluted). Infected cells were further characterized by the staining for E-cadherin (red) (D, E). (F) Total RNA was isolated from the supernatants and cell lysates of infected and uninfected ATE cells at 24 h.p.i. The cDNA derived from viral sense $(+)$ and antisense RNA (-) were detected by primers targeting to the nucleocapsid (N) gene. The house-keeping gene GAPDH was used as an internal control. Scar bar in panel (A) to (C), $25 \mu \mathrm{m}$; in panel D and E, $10 \mu \mathrm{m}$. (A color version of this figure is available at www.vetres.org.)

\section{DISCUSSION}

In this study, we showed that primary ATE cells exhibit the same cell composition as tracheal epithelia and can be passaged and amplified in a convenient and efficient way. These cells support IBV viral replication and viral release, providing an ideal system to amplify respiratory viruses and characterize their pathogenesis.

In studies of tracheal infection, ciliated cells and goblet cells have been shown to be the major target cells of IBV $[1,22]$. Our results with primary ATE cells also showed that IBV viral protein can be detected in both ciliated cells and goblet cells. This cell tropism may account for the pathogenesis of IBV, such as the ciliostasis in observed IBV-infected TOC and the reduction of sialic acid secretion [3, 22]. In addition, we are the first to demonstrate that IBV does not appear to infect K14-positive basal cells. In an uncomplicated IBV-infected chick, clinical signs such as gasping, coughing, tracheal rales and nasal discharge persist for only 5-to-7 days and disappear within 2 weeks [3, 22]. In the recovery stage, unaffected basal cells may be responsible for epithelial hyperplasia after desquamation of the ciliated and goblet cells and reconstruction of the epithelium of the injured respiratory tract to reestablish normal physiological functioning $[12,13,22]$. The insensitivity of basal cells to IBV infection also suggests that coinfection with other viral or bacterial pathogens is required to disrupt basal membrane integrity and cause hemorrhage in IBV-infected tracheas. 

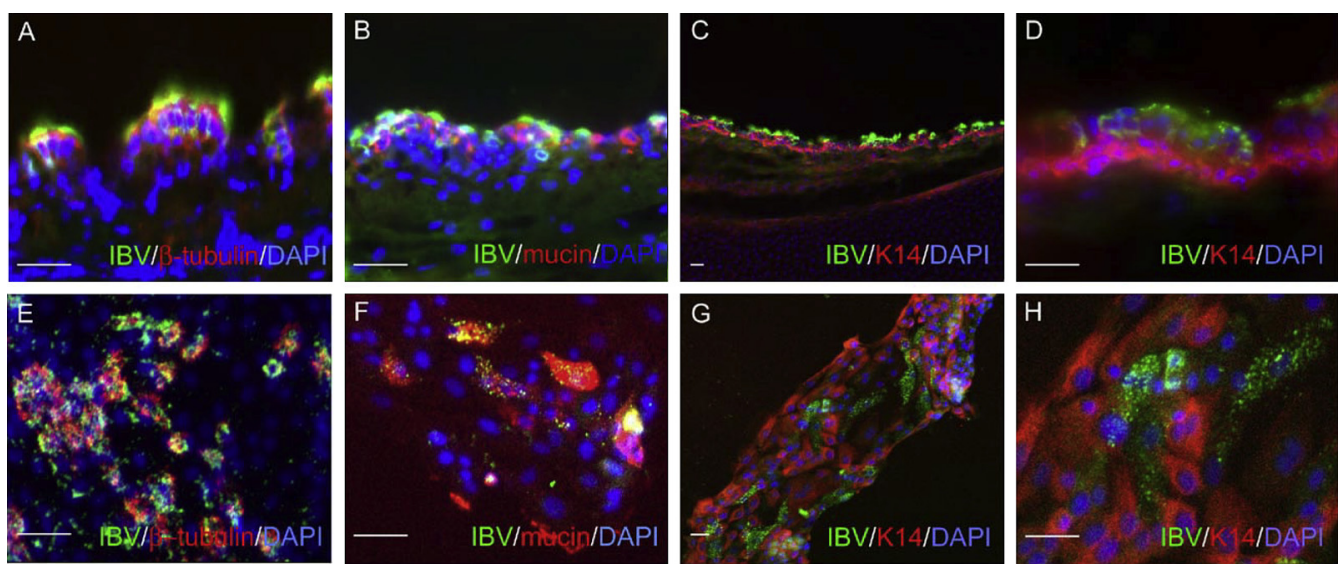

Figure 4. IBV infects ciliated cells and goblet cells, but not basal cells. At 48 h.p.i. with IBV, double staining for IBV proteins and $\beta$-tubulin (A, E), mucin5AC (B, F) or K14 (C, G) was performed in cryosectioned tracheal tissues (A-D) and ATE cells $(E-H)$. Panels $(D)$ and $(H)$ are higher magnifications of panels $(\mathrm{C})$ and $(\mathrm{G})$, respectively. Scar bar, $20 \mu \mathrm{m}$. (A color version of this figure is available at www.vetres.org.)

A

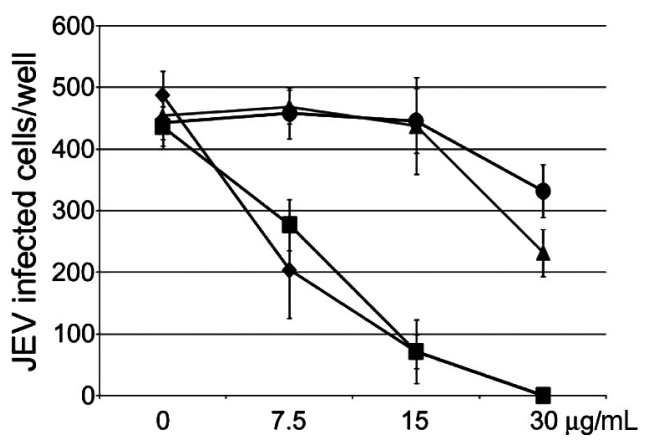

B

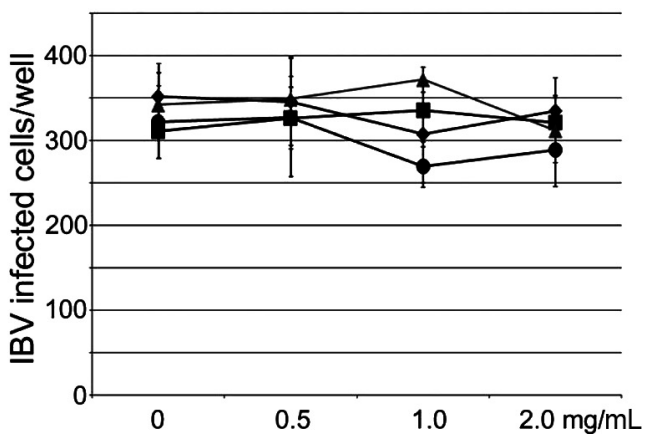

Figure 5. Infection of ATE cells with IBV is not significantly affected by GAG. The effects of GAG on JEV and IBV infections were measured in BHK-21 cells (A) and ATE cells (B), respectively. The cells were seeded at a density of $5 \times 10^{3}$ cells/well in 96-well plates. The GAG were serially diluted and applied to BHK-21 cells and ATE cells prior to infection with 500 PFU of JEV and $10^{3} \mathrm{EID}_{50}$ of IBV at $37{ }^{\circ} \mathrm{C}$ for $1 \mathrm{~h}$. The infected cells were fixed at 8 h.p.i. The number of infected cells was manually counted after immunocytostaining for IBV antigens. The data represent the average of triplicate wells under the same experimental conditions.

At present, quantification of the virulence of IBV is still a problem [3, 22]. Measuring ciliostasis in TOC is not a sensitive approach for determining the severity of respiratory tract injury caused by IBV infection [21]. In addition, different species of chicken may also vary in the vulnerability of their respiratory tissue to
IBV infection $[2,22]$. In our ATE system, IBV shows high affinity for ciliated cells and goblet cells. Cell tropism, viral replication and viral spread can be determined and quantified by immunocytostaining, suggesting that ATE cells could serve as a quantitative platform to determine the pathogenesis of IBV. 
It has been shown that sialic acid and HS may help IBV bind to its receptor on the cell membrane of target cells [18, 32]. Receptor binding triggers endocytosis and delivers the viral genome into the cytosol through $\mathrm{pH}$ dependent membrane fusion [4]. In this study, we demonstrate that none of the tested GAG interfered with IBV binding to ATE cells. Further investigation is required to test whether this ineffectiveness is due to a lack of the XBBXBX $\mathrm{H}$ consensus sequence in the $\mathrm{S}$ protein sequences of TW IBV.

In this study, we established a primary ATE cell culture system for the maintenance and amplification of epithelial cells of the chicken respiratory tract. Using these culture conditions, immortalized cell lines could potentially be established by overexpression of oncogenes, telomerase or anti-apoptotic genes. Both primary cells and respiratory cell lines will provide a new window to reveal viral life cycles, viral persistence, virus-cell interaction and the pathogenesis of avian respiratory viruses.

Acknowledgements. The funding for this project was provided by the Bureau of Animal and Plant Health Inspection and Quarantine, Council of Agriculture in Taiwan (H.L.S.). We thank Dr Yi-Ling Lin (Academic Sinica, Taiwan) for providing the JEV, critical reading of the manuscript and invaluable comments. We also thank the support from Center of Tissue Engineering and Stem Cells, NCHU.

\section{REFERENCES}

[1] Abd El Rahman S., El-Kenawy A.A., Neumann U., Herrler G., Winter C., Comparative analysis of the sialic acid binding activity and the tropism for the respiratory epithelium of four different strains of avian infectious bronchitis virus, Avian Pathol. (2009) 38:41-45.

[2] Bumstead N., Huggins M.B., Cook J.K., Genetic differences in susceptibility to a mixture of avian infectious bronchitis virus and Escherichia coli, $\mathrm{Br}$. Poult. Sci. (1989) 30:39-48.

[3] Cavanagh D., Coronavirus avian infectious bronchitis virus, Vet. Res. (2007) 38:281-297.

[4] Chu V.C., McElroy L.J., Chu V., Bauman B.E., Whittaker G.R., The avian coronavirus infectious bronchitis virus undergoes direct low-pH-dependent fusion activation during entry into host cells, J. Virol. (2006) 80:3180-3188.

[5] Cook J.K., Avian pneumovirus infections of turkeys and chickens, Vet. J. (2000) 160:118-125.

[6] Cook J.K., Cavanagh D., Detection and differentiation of avian pneumoviruses (metapneumoviruses), Avian Pathol. (2002) 31:117-132.

[7] Crinion R.A., Hofstad M.S., Pathogenicity of two embryo-passage levels of avian infectious bronchitis virus for the oviduct of young chickens of various ages, Avian Dis. (1972) 16:967-973.

[8] Gambaryan A.S., Robertson J.S., Matrosovich M.N., Effects of egg-adaptation on the receptorbinding properties of human influenza $\mathrm{A}$ and $\mathrm{B}$ viruses, Virology (1999) 258:232-239.

[9] Gubareva L.V., Wood J.M., Meyer W.J., Katz J.M., Robertson J.S., Major D., Webster R.G., Codominant mixtures of viruses in reference strains of influenza virus due to host cell variation, Virology (1994) 199:89-97.

[10] Hill E.M., Bader T., Nettesheim P., Eling T.E., Retinoid-induced differentiation regulates prostaglandin $\mathrm{H}$ synthase and cPLA2 expression in tracheal epithelium, Am. J. Physiol. (1996) 270:L854-L862.

[11] Hinshaw V.S., Nettles V.F., Schorr L.F., Wood J.M., Webster R.G., Influenza virus surveillance in waterfowl in Pennsylvania after the H5N2 avian outbreak, Avian Dis. (1986) 30:207-212.

[12] Hong K.U., Reynolds S.D., Watkins S., Fuchs E., Stripp B.R., Basal cells are a multipotent progenitor capable of renewing the bronchial epithelium, Am. J. Pathol. (2004) 164:577-588.

[13] Hong K.U., Reynolds S.D., Watkins S., Fuchs E., Stripp B.R., In vivo differentiation potential of tracheal basal cells: evidence for multipotent and unipotent subpopulations, Am. J. Physiol. (2004) 286:L643-L649.

[14] Huang Y.P., Wang C.H., Development of attenuated vaccines from Taiwanese infectious bronchitis virus strains, Vaccine (2006) 24:785-791.

[15] Ito T., Suzuki Y., Takada A., Kawamoto A., Otsuki K., Masuda H., et al., Differences in sialic acidgalactose linkages in the chicken egg amnion and allantois influence human influenza virus receptor specificity and variant selection, J. Virol. (1997) 71:3357-3362.

[16] Kodihalli S., Justewicz D.M., Gubareva L.V., Webster R.G., Selection of a single amino acid substitution in the hemagglutinin molecule by chicken eggs can render influenza A virus $(\mathrm{H} 3)$ candidate vaccine ineffective, J. Virol. (1995) 69:4888-4897. 
[17] Krauss S., Obert C.A., Franks J., Walker D., Jones K., Seiler P., et al., Influenza in migratory birds and evidence of limited intercontinental virus exchange, PLoS Pathog. (2007) 3:e167.

[18] Madu I.G., Chu V.C., Lee H., Regan A.D., Bauman B.E., Whittaker G.R., Heparan sulfate is a selective attachment factor for the avian coronavirus infectious bronchitis virus Beaudette, Avian Dis. (2007) 51:45-51.

[19] Otsuki K., Takemoto O., Fujimoto R., Yamazaki K., Kubota N., Hosaki H., et al., Isolation of influenza A viruses from migratory waterfowl in San-in District, western Japan in the winter of 1983-1984, Res. Vet. Sci. (1987) 43:177-179.

[20] Otsuki K., Yamazaki K., Kawaoka Y., Tsubokura M., Intracerebral pathogenicity for chickens of avian influenza viruses isolated from free-living waterfowl in Japan, Vet. Microbiol. (1988) 18:357-362.

[21] Raj G.D., Jones R.C., An in vitro comparison of the virulence of seven strains of infectious bronchitis virus using tracheal and oviduct organ cultures, Avian Pathol. (1996) 25:649-662.

[22] Raj G.D., Jones R.C., Infectious bronchitis virus: immunopathogenesis of infection in the chicken, Avian Pathol. (1997) 26:677-706.

[23] Rowe R.K., Brody S.L., Pekosz A., Differentiated cultures of primary hamster tracheal airway epithelial cells, In vitro (2004) 40:303-311.

[24] Saito T., Nakaya Y., Suzuki T., Ito R., Saito T., Saito H., et al., Antigenic alteration of influenza B virus associated with loss of a glycosylation site due to host-cell adaptation, J. Med. Virol. (2004) 74: 336-343.

[25] Silvano F.D., Yoshikawa M., Shimada A., Otsuki K., Umemura T., Enhanced neuropathogenicity of avian influenza A virus by passages through air sac and brain of chicks, J. Vet. Med. Sci. (1997) 59: 143-148.

[26] Slemons R.D., Condobery P.K., Swayne D.E., Assessing pathogenicity potential of waterfowl-origin type A influenza viruses in chickens, Avian Dis. (1991) 35:210-215.

[27] Stemple D.L., Anderson D.J., Isolation of a stem cell for neurons and glia from the mammalian neural crest, Cell (1992) 71:973-985.

[28] Su C.M., Liao C.L., Lee Y.L., Lin Y.L., Highly sulfated forms of heparin sulfate are involved in japanese encephalitis virus infection, Virology (2001) 286:206-215.

[29] Wang C.H., Tsai C.T., Genetic grouping for the isolates of avian infectious bronchitis virus in Taiwan, Arch. Virol. (1996) 141:1677-1688.

[30] Wang C.H., Huang Y.C., Relationship between serotypes and genotypes based on the hypervariable region of the $\mathrm{S} 1$ gene of infectious bronchitis virus, Arch. Virol. (2000) 145:291-300.

[31] Widjaja L., Krauss S.L., Webby R.J., Xie T., Webster R.G., Matrix gene of influenza a viruses isolated from wild aquatic birds: ecology and emergence of influenza a viruses, J. Virol. (2004) 78: 8771-8779.

[32] Winter C., Schwegmann-Wessels C., Cavanagh D., Neumann U., Herrler G., Sialic acid is a receptor determinant for infection of cells by avian Infectious bronchitis virus, J. Gen. Virol. (2006) 87: 1209-1216.

[33] Zaffuto K.M., Estevez C.N., Afonso C.L., Primary chicken tracheal cell culture system for the study of infection with avian respiratory viruses, Avian Pathol. (2008) 37:25-31. 